\title{
The Detection of Bovine Lactoferrin Binding Protein on Toxoplasma gondii
}

\author{
Tetsuya TANAKA ${ }^{1)}$, Yukie ABE ${ }^{1}$, Woan-Sub KIM ${ }^{1)}$, Xuenan XUAN²), Hideyuki NAGASAWA ${ }^{2)}$, Ikuo IGARASHI', \\ Haruto KUMURA $^{1)}$ and Kei-ichi SHIMAZAKI ${ }^{1)}$ \\ ${ }^{1)}$ Dairy Science Laboratory, Graduate School of Agriculture, Hokkaido University, Sapporo, Hokkaido 060-8589 and ${ }^{2)}$ The Research \\ Center for Protozoan Diseases, Obihiro University of Agriculture and Veterinary Medicine, Obihiro, Hokkaido 080-8555, Japan
}

(Received 1 April 2003/Accepted 20 August 2003)

ABSTRACT. Lactoferrin (LF), a member of the transferrin (TF) protein family, is an iron-binding protein that is known to interact with bac teria through a specific receptor. We examined the binding of bovine LF (bLF), bovine TF (bTF), and ovotransferrin (OTF) by Toxoplasma gondii using a fluorescence test and the streptavidin-biotin (SAB) method using biotin-streptavidin, and found that bLF, bTF, and OTF bound to the protein components of $T$. gondii. Furthermore, we confirmed that bLF, bTF, and OTF bound a $42 \mathrm{kDa}$ soluble protein of $T$. gondii by far Western blot method. These results demonstrated that bLF binding proteins are present on $T$. gondii. KEY WORDS: lactoferrin, Toxoplasma gondii, transferrin family protein.

Toxoplasma gondii, an intracellular parasitic protozoa, can penetrate mammalian and avian somatic cells. In the host cells, the $T$. gondii parasites are enclosed in parasitophorous vacuoles, which allows them to evade fusion with lysosomes and enables their growth even in macrophages [11]. Macrophages possess oxygen-dependent and oxygenindependent anti-protozoan mechanisms. Interferon- $\gamma$ (IFN- $\gamma$ ) enhances the oxygen-dependent elimination of intracellular $T$. gondii through the synthesis of inorganic nitrogen oxide from L-arginine. Furthermore, treatment of macrophages with IFN- $\gamma$ depletes intracellular iron stores by decreasing transferrin (TF) receptor expression in intracellular pathogens including Legionella pneumophila and Histoplasma capsulatum $[1,5,13]$, although others (e.g. T. gondii, Chalamydia psittaci, and Leishmania donovani) remain unaffected [15]. These differences in sensitivity may reflect whether the intracellular pathogen utilized iron derived from an intra- or an extracellular source. Therefore, the data suggest that $T$. gondii obtains iron from $\mathrm{TF}$ via a TF receptor.

Lactoferrin (LF), a cationic iron-binding protein that is produced and secreted by mammary glands and neutrophils, exhibits a broad spectrum of antimicrobial properties $[2,4$, $6]$. Because protozoan parasites require iron for growth and development, the sequestration of free iron by LF may provide an important nonspecific host defense mechanism that starves microorganisms of this essential element. However, some microorganisms, including trichomonads, have adapted to use LF as a source of iron. The vaginal tract pathogens Trichomonas vaginalis and Tricomonas foetus, acquire iron from LF via a specific $136 \mathrm{kDa}$ or $155 \mathrm{kDa}$ receptor, respectively, found on the cell surface [7, 14]. Iron from LF could be transported to $T$. gondii through normal or unique transport mechanisms of parasitized mammalian host cells. Therefore, in this short report, we thought that LF functions as a bridge molecule between these proteins and $T$. gondii, and demonstrated the presence of bLF binding proteins in $T$. gondii.
Complete protease inhibitor (Boehringer Mannheim, Mannheim, Germany), fluorescein conjugated-avidin (avidin-FITC), N-hydroxysuccinimide biotin, o-phenylenediamine (Sigma Chemicals Co., St. Louis, MO), horseradish peroxidase conjugated-streptavidin (streptavidin-HRP) (Nichirei Co., Tokyo, Sigma Chemicals Co.), bovine serum albumin (BSA), bovine iron deficient (apo)-transferrin (bTF), ovotransferrin (OTF) (iron free type, Sigma Chemicals Co.), and bovine iron deficient (apo)-lactoferrin (bLF) (Morinaga Milk Co., Zama) were used as described below. The ECL reagent kit (Amersham Bioscience Co., Piscataway, $\mathrm{NJ}$ ) was used to detect chemiluminescence.

Tachyzoites of $T$. gondii $\mathrm{RH}$ strain were maintained by continuous passage through Vero cells. About $1 \times 10^{6}$ parasites $/ \mathrm{m} l$ were introduced into the cell culture, and after 2-3 days of cultivation, parasites were collected and purified using 5- $\mu \mathrm{m}$ Nucleopore filters (Sartorius Ag, Gottingen, Germany). The purified-parasite suspension was centrifuged and the supernatant was removed. The pelleted parasites were counted using a hemocytometer and washed three times with phosphate-buffered saline (PBS). Finally, the parasites were dispersed into fresh tubes at a ratio of $1 \times 10^{8}$ cells per tube. The tubes containing the parasites were stored at $-80^{\circ} \mathrm{C}$ until use in the following experiments.

Soluble proteins were extracted from parasites using the following method. The cell pellets were suspended in $50 \mu \mathrm{ll}$ tube of RIPA buffer (10 mM Tris- $\mathrm{HCl}$ pH 7.4, $150 \mathrm{mM}$ $\mathrm{NaCl}, 5$ mM EDTA pH 8.0, 1\% Triton X-100, 0.1\% SDS) containing complete protease inhibitor. After incubating overnight at $4^{\circ} \mathrm{C}$, the cell lysates were centrifuged at 11,000 $\mathrm{g}$ for $30 \mathrm{~min}$ to obtain supernatants containing the soluble fraction.

To prepare biotinylated proteins, N-hydroxysuccinimide biotin was dissolved at a concentration of $10 \mathrm{mg} / \mathrm{ml}$ in dimethyl sulfoxide and the proteins (bLF, bTF, and OTF) were dissolved at a concentration of $3 \mathrm{mg} / \mathrm{m} l$ in $0.1 \mathrm{M}$ sodium borate buffer ( $\mathrm{pH} 8.8$ ). The biotin ester was then added at a ratio of $250 \mu \mathrm{g}$ of biotin ester per $1 \mathrm{mg}$ of protein, mixed 
well and incubated at room temperature for $4 \mathrm{hr}$. Finally, 20 $\mu l$ of $1 \mathrm{M} \mathrm{NH}_{4} \mathrm{Cl}$ per $250 \mu \mathrm{g}$ of biotin ester was added and the solution was incubated at room temperature for $10 \mathrm{~min}$. After incubation, the reaction mixture was dialyzed extensively against PBS to remove the unreacted reagent. The estimated biotinylation ratio was $32 \%$ of total amino groups based on the molecular mass measured by matrix assisted laser desorption ionization-time of flight mass spectrum.

Protein binding on $T$. gondii was assayed using a fluorescence test. Toxoplasma gondii tachyzoites were fixed with acetone and incubated with biotinylated bLF (bLF-bio), biotinylated bTF (bTF-bio), or biotinylated OTF (OTF-bio) at $37^{\circ} \mathrm{C}$ for $30 \mathrm{~min}$ at a concentration of $10 \mu \mathrm{g} / \mathrm{ml}$ in dilution buffer containing $3 \% \mathrm{BSA}$ and $0.05 \% \mathrm{NaN}_{3}$ in PBS. Then, the cells were washed three times with PBS and incubated in avidin-FITC at $37^{\circ} \mathrm{C}$ for $30 \mathrm{~min}$, which was diluted 200 times with the dilution buffer. The cells were again washed three times and observed under a TCS-NT confocal laser scanning microscope (Leica Geosytems, Tokyo).

A protein binding assay using the streptavidin-biotin (SAB) method was carried out as follows. Ninety-six well microtiter plates (Corning Inc., Corning, NY) were coated with $50 \mu l$ of whole $T$. gondii tachyzoites lysates $\left(1 \times 10^{7} /\right.$ $\mathrm{m} l$ ) in $0.05 \mathrm{M}$ carbonate-bicarbonate buffer ( $\mathrm{pH}$ 9.6) overnight at $4{ }^{\circ} \mathrm{C}$, washed once with PBS containing $0.05 \%$ Tween 20 (PBST), and blocked with $100 \mu \mathrm{l}$ of PBS diluted in $3 \% \mathrm{BSA}$ for $1 \mathrm{hr}$ at $37^{\circ} \mathrm{C}$. After washing with PBST, bLF-bio, bTF-bio, or OTf-bio were added at a concentration of $10 \mu \mathrm{g} / \mathrm{m} l$ to each well in $50 \mu l$ volumes. The plates were incubated for $1 \mathrm{hr}$ at $37^{\circ} \mathrm{C}$ and washed six times with PBST. A $50 \mu \mathrm{l}$ aliquot of streptavidin-HRP diluted 1:10,000 was added to each well and again incubated for $1 \mathrm{hr}$ at $37^{\circ} \mathrm{C}$. The wells were then washed with PBST six times, and 100 $\mu l$ of substrate $(0.1 \mathrm{M}$ citric acid, $0.2 \mathrm{M}$ sodium phosphate, $0.003 \% \mathrm{H}_{2} \mathrm{O}_{2}$ and $0.4 \mathrm{mg} / \mathrm{ml} \mathrm{o}$-phenylenediamine) were used for color development. After $1 \mathrm{hr}$, the optical density (O.D.) was read at $492 \mathrm{~nm}$ on a MTP-120 plate reader (TOSOH, Tokyo).

A competitive inhibition assay using the SAB method was performed as follows. After blocking, a 2-fold serial dilution of bLF in PBS was added into the wells as an inhibitor and mixed with bLF-bio, bTF-bio, or OTf-bio at a concentration of $10 \mu \mathrm{g} / \mathrm{ml}$ in volumes of $50 \mu l$. After a $1 \mathrm{hr}$ incubation at $37^{\circ} \mathrm{C}$, the plates were washed six times in PBST, and $50 \mu l$ streptavidin-HRP, diluted 10,000 times in PBS, was added into the wells and incubated for $1 \mathrm{hr}$ at $37^{\circ} \mathrm{C}$. The plates were washed six times with PBST and 100 $\mu l$ of substrate was added for color development. After $1 \mathrm{hr}$, the O.D. was read at $492 \mathrm{~nm}$ on a micro plate reader.

Far Western blotting was carried out as follows. SDSPAGE analysis was performed on a $10 \%$ polyacrylamide gel according to Laemmli's method [12]. The proteins were boiled for $5 \mathrm{~min}$ in sample buffer $(62.5 \mathrm{mM}$ Tris- $\mathrm{HCl} \mathrm{pH}$ $6.8,2 \% \mathrm{SDS}, 5 \%$ beta-mercaptoethanol, $10 \%$ glycerol, $0.02 \%$ bromophenol blue). After SDS-PAGE, the proteins were blotted onto a PVDF membrane (Osmonics Inc., Westborough, MA). Electroblotting was performed for $1 \mathrm{hr}$ at room temperature in a $25 \mathrm{mM}$ Tris, $192 \mathrm{mM}$ glycine, $20 \%$ ethanol buffer at $2 \mathrm{~mA} / \mathrm{cm}^{2}$. The blotted PVDF membrane was blocked with the blocking buffer (1\% BSA in PBS) for $1 \mathrm{hr}$ at room temperature. After blocking, the membrane was incubated with biotinylated proteins at a concentration of $1 \mu \mathrm{g} / \mathrm{m} l$ in blocking buffer at $4{ }^{\circ} \mathrm{C}$ overnight. The membrane was then washed five times in washing buffer $(0.05 \%$ Tween 20 in PBS) and incubated at room temperature for 30 min with streptavidin-HRP diluted 1:800 in blocking buffer. Subsequently, the membrane was washed five times in washing buffer and the protein bands were visualized on $\mathrm{X}$ ray film using the ECL kit according to the manufacturer's protocol.

We assayed the binding of bLF-bio, bTF-bio, and OTFbio by $T$. gondii using a fluorescence test and observed fluorescent signals in response to all three biotinylated proteins (Fig. 1). The control signal was substantially weaker than the signals from the biotinylated proteins. These results suggested the presence of these binding proteins on the parasite. As shown in Fig. 2, the SAB assay confirmed the presence of bLF-bio, bTF-bio, and OTF-bio on T. gondii. However, whether or not the two assays recognized the same molecules on $T$. gondii, was unclear. For clarification, we performed a competitive inhibition assay using the 96well plate prepared for the SAB assay. As shown in Fig. 3, the addition of excess bLF as an inhibitor increased the inhibition rate of absorbance in the reaction mixtures and suggested that bTF and OTF recognize the same proteins as bLF.

In order to confirm these observations, we detected the bLF binding proteins of $T$. gondii using far Western blotting. As shown in Fig. 4, only one protein band exhibiting a molecular mass of $42 \mathrm{kDa}$ was observed the in soluble fraction of $T$. gondii treated with RIPA buffer.

TF uptake by Trypanosoma brucei has been well characterized. In this parasite, the ESAG6 and ESAG7 gene products associate into a hetero dimeric TF binding protein complex (TFBP) [19, 20]. ESAG6 is a heavily glycosylated 50-60 kDa molecule anchored to the membrane by a glycosyl-phosphatidylinositol anchor, whereas the $42 \mathrm{kDa}$ glycoprotein ESAG7 is unmodified at its C-terminus. The TFBP complex can confer the ability to bind iron saturated (holo)TF, although neither ESAG6 nor ESAG7 alone can facilitate TF binding. Binding of holo-TF to mammalian cell TF receptors is followed by internalization of receptor-ligand complexes and subsequent acidification in an endosomal compartment. Iron is released from TF under acidic conditions and is retained intracellularly, whereas apo-TF remains associated with its receptor and recycles back to the cell surface. Neutral $\mathrm{pH}$ causes dissociation of apo-TF from its receptor and results in extracellular release of the protein. In contrast, the $T$. brucei TFBP-TF complex is internalized and transported to lysosomes, where $\mathrm{TF}$ is proteolytically degraded. Thus, trypanosomal and mammalian holo-TF uptake processes differ in the fate of internalized TF and in their dependence on $\mathrm{pH}$ recycling.

The presence of TF receptors on intracellular forms of 
A

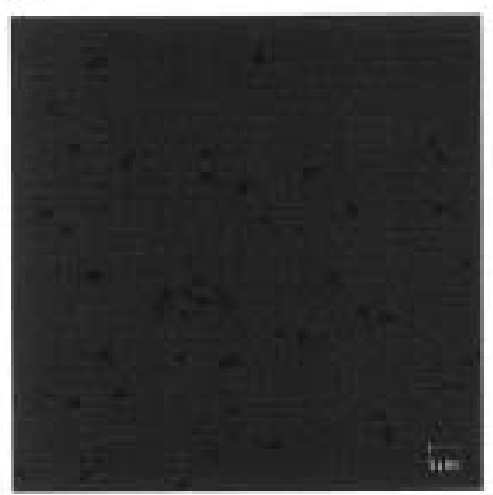

C

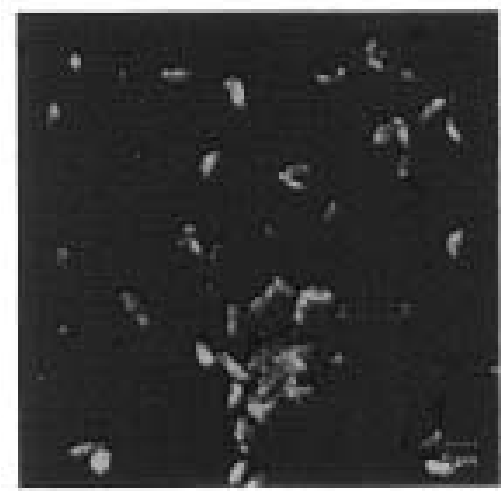

B

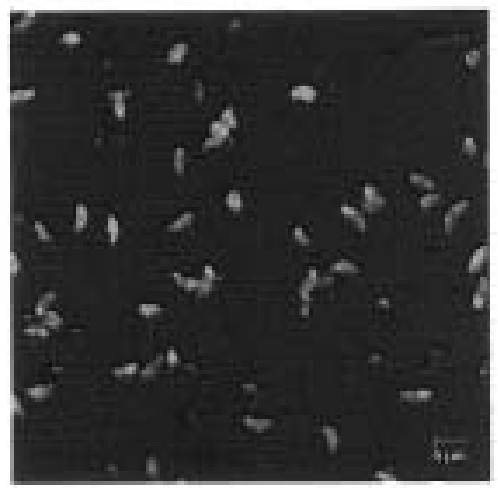

D

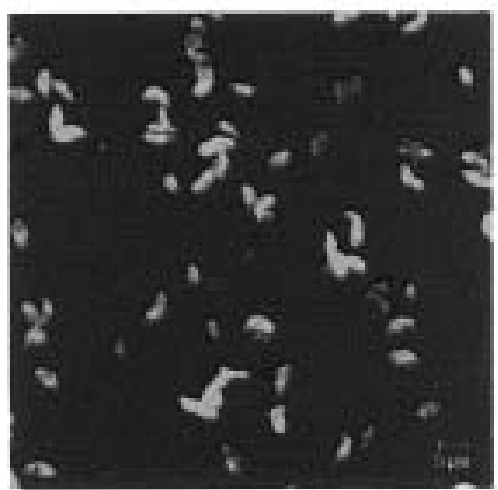

Fig. 1. Florescence staining of T. gondii using biotinylated proteins. After the parasites were reacted with controls (avidin-FITC only) (A), bLF-bio (B), bTF-bio (C) and OTF-bio (D), the avidin-FITC reaction was observed by confocal laser microscopy.

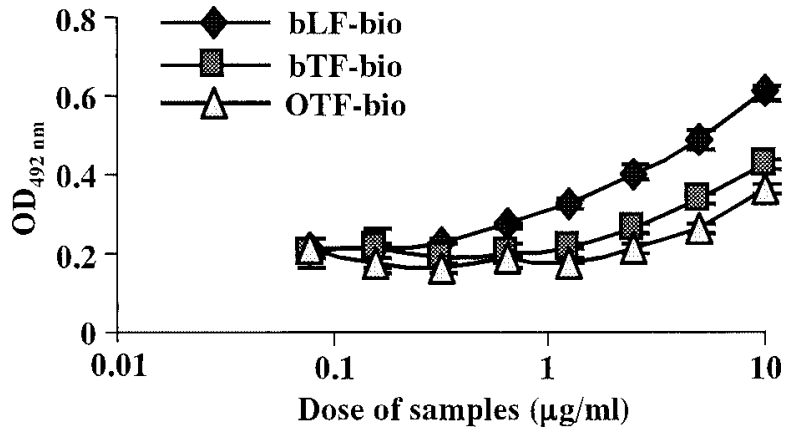

Fig. 2. bLF-bio, bTF-bio and OTF-bio binding assay. The wells were coated with whole $T$. gondii proteins, reacted with biotinylated proteins, and detected by streptavidin-HRP. Each value represents the mean \pm S.D. of triplicate samples.

Plasmodium spp. has been debated, and conflicting evidence has been presented regarding the entry of holo-TF into Plasmodium falciparum parasitophorous [9, 17]. Several groups have found that the parasite does not use iron bound to TF, and the mechanism of iron utilization remains

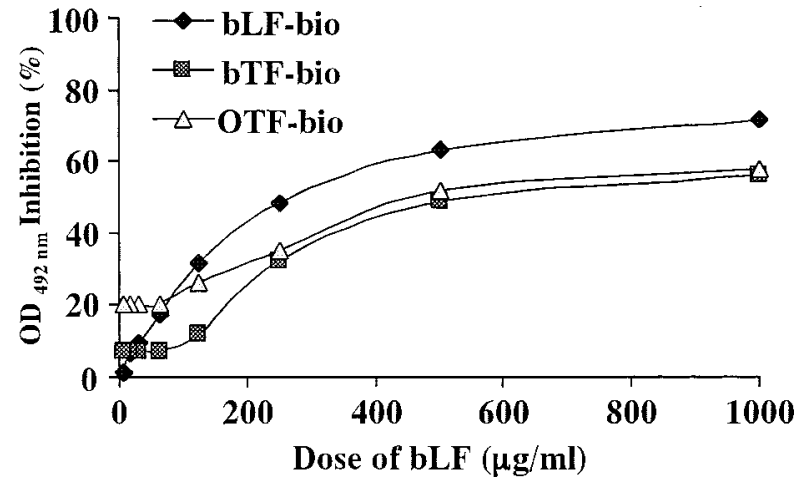

Fig. 3. The competitive inhibition assay for the binding of bLFbio, bTF-bio, and OTF-bio to the T. gondii proteins using bLF as the inhibitor. The wells were coated with whole $T$. gondii proteins and reacted with bLF as an inhibitor. bLF-bio, bTF-bio and OTF-bio were detected by streptavidin-HRP. The results are presented as the inhibition rate of absorbance to the bLF ( 0 $\mu \mathrm{g} / \mathrm{ml}$ ) value. Each value represents the average value of triplicate samples. S.D were $<8 \%$. 


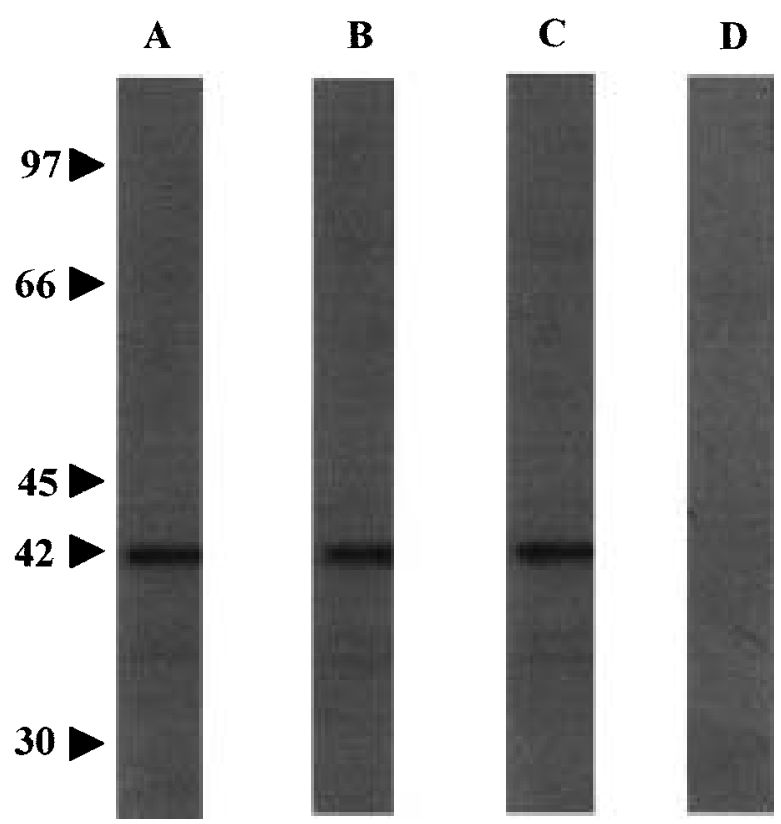

Fig. 4. The binding of bLF-bio (A), bTF-bio (B), OTF-bio(C) and streptavidin-HRP only (D) to $T$. gondii proteins was detected by far Western blotting. The parasite proteins were extracted from $T$. gondii by RIPA buffer. Molecular weight is given in $\mathrm{kDa}$.

unclear $[16,18]$. The LF binding protein could be expected to play a biological role in growth promotion, because such binding proteins have been found on the cell surface of many microorganisms [8] and on mammalian cells from various tissues $[3,10]$. Iron acquisition by parasites may be mediated by parasitic LF binding proteins. However, in the present experiments, we showed that iron content does not influence the apo-LF binding. Our previous study showed that despite iron deficiency or iron saturation, murine somatic cells incubated in media containing LF inhibit intracellular parasites [22]. The mechanism behind this inhibition is, however, still unclear. Moreover, bLF does not directly influence the viability of $T$. gondii [21]. Further studies will be required to determine whether the LF and binding protein complex of $T$. gondii can interact with the promotion or inhibition of iron uptake in $T$. gondii.

ACKNOWLEDGEMENTS. This work was supported by grant from the Japan Society for the Promotion of Science (Grant-in-Aid for Encouragement of Young Scientists B) and the Hokusaitic Scientific Research Grant.

\section{REFERENCES}

1. Alford, C. E., King, T. E. Jr. and Campbell, P. A. 1991. J. Exp. Med. 174: 459-466.

2. Bellamy, W., Takase, M., Yamauchi, K., Wakabayashi, H., Kawase, K. and Tomita, M. 1992. Biochim. Biophys. Acta 1121: 130-136.

3. Brock, J. 1995. Immunol. Today 16: 417-419.

4. Bullen, J. J., Rogers, H. J. and Leigh, L. 1972. Br. Med. J. 1: 69-75.

5. Byrd, T. F. and Horwitz, M. A. 1989. J. Clin. Invest. 83: $1457-$ 1465.

6. Ellison, R. T., Giehl, T. J. and LaForce, F. M. 1988. Infect. Immun. 56: 2774-2781.

7. Grab, D. J., Lonsdale-Eccles, J. D., Oli, M. W. and Corbeil, L. B. 2001. J. Parasitol. 87: 1064-1070.

8. Gray-Owen, S. D. and Schryvers, A. B. 1996. Trends Microbiol. 4: 185-191.

9. Haldar, K., Henderson, C. L. and Cross, G. A. 1986. Proc. Natl. Acad. Sci. U.S.A. 83: 8565-8569.

10. Iyer, S. and Lonnerdal, B. 1993. Eur. J. Clin. Nutr. 47: 232 241.

11. Jones, T. C. and Hirsch, J. G. 1972. J. Exp. Med. 136: 11731194.

12. Laemmli, U. K. 1970. Nature (Lond.) 227: 680-685.

13. Lane, T. E., Wu-Hsieh, B. A. and Howard, D. H. 1991. Infect. Immun. 59: 2274-2278.

14. Lehker, M. W. and Alderete, J. F. 1992. Mol. Microbiol. 6: 123-132.

15. Murray, H. W., Granger, A. M. and Teitelbaum, R. F. 1991. Infect. Immun. 59: 4684-4686.

16. Pollack, S. and Schnelle, V. 1988. Br. J. Haematol. 68: 125129.

17. Rodriguez, M. H. and Jungery, M. 1986. Nature (Lond.) 324: 388-391.

18. Salmon, D., Geuskens, M., Hanocq, F., Hanocq-Quertier, J., Nolan, D., Ruben, L. and Pays, E. 1994. Cell 78: 75-86.

19. Sanchez-Lopez, R. and Haldar, K. 1992. Mol. Biochem. Parasitol. 55: 9-20.

20. Steverding, D., Stierhof, Y. D., Fuchs, H., Tauber, R. and Overath, P. 1995. J. Cell Biol. 131: 1173-1182.

21. Tanaka, T., Omata, Y., Saito, A., Shimazaki, K., Yamauchi, K., Takase, M., Kawase, K., Igarashi, I. and Suzuki, N. 1995. Exp. Parasitol. 81: 614-617.

22. Tanaka, T., Omata, Y., Saito, A., Shimazaki, K., Igarashi, I. and Suzuki, N. 1996. J. Vet. Med. Sci. 58: 61-65. 